\title{
Sustainable Development and ICT Use Among Elderly: A Comparison Between the Netherlands and Italy
}

\author{
Paola Monachesi $\left.{ }^{(}\right)$ \\ Utrecht University, Trans 10, 3512 JK Utrecht, The Netherlands \\ P. Monachesi@uu.nl
}

\begin{abstract}
The paper analyzes the participation of the elderly in the digital society by comparing the situation in the Netherland and in Italy. While the Netherlands are at the forefront in internet and social media use with $80 \%$ of the seniors in the age group 65-75 being online in 2016, the situation is different in Italy with only $28,8 \%$ of the population in this age group using Internet. We have carried out two surveys in Italy to highlight the reasons for this difference which seems to be due to lack of digital competences. We suggest that the widespread use of ICT in The Netherlands can have a positive impact on urban sustainability and on healthy ageing through caring and volunteering activities of the elderly in the natural environment promoted through social media.
\end{abstract}

Keywords: Social media $\cdot$ Internet $\cdot$ Elderly $\cdot$ Urban sustainability $\cdot$ Italy $\cdot$ The Netherlands

\section{Introduction}

The elderly are usually considered a problem for sustainable development since the exponential growth of the ageing population threatens the resources that are globally available [1]. In the context of the European project Grage [2], we have carried out an interdisciplinary research on the challenges of ageing and sustainable development in urban areas. The study has evolved around the idea of citizenship, healthy environment and suitable urban solutions for an ageing society. The themes addressed in the project are elderly legal rights, green urbanization, food sustainability and analysis of elderly urban behavior. In this context, we have investigated the role that information and language technology can have in transforming cities into environments that support green and healthy lifestyles.

The elderly can be a resource for sustainable development if we stimulate their involvement in reducing the environmental footprint as well as their volunteering activities in a natural environment, an important aspect of healthy ageing [3]. Internet and social media can play an important role in supporting these best practices: they are affecting the way we live in urban areas since many activities such as social interactions, production, consumption and exchange of services, are now also occurring in online spaces. More specifically, information and language technology can play an important role in the promotion of sustainable development based on a behavioral 
analysis of the data produced by old adults. Therefore, we adopt the view that cities are characterized by the connectivity of the people and the digital devices that make them important data producers, especially through social media, allowing thus an analysis of the content and of the interactions of the users. These data can provide useful insights to deal with current issues in green economy, healthy lifestyles and healthy ageing and more generally they can help redefine urban spaces. In this context, the participation of the elderly in the digital society is essential, however, there are still crucial differences at European level in this respect.

In this paper, we analyze the situation with respect to ICT use by focusing on a comparison between the Netherlands and Italy, two countries with quite different behavior. It is based on data available from the respective national statistical institutes (i.e. CBS and ISTAT, respectively) and from two surveys we have carried out in Italy within the Grage project. We show that the Netherlands are at the forefront in Internet and social media use even among the elderly, while this is not the case in Italy where Internet and social media adoption are lagging behind and we investigate the reasons for this difference.

\section{ICT Use Among Elderly in the Netherlands}

The knowledge economy is a growing sector in the Netherlands: companies use social media extensively to communicate with their clients that are quite often online. Eight out of ten Dutch citizens use mobile internet on a daily basis: while Internet use is pervasive in the youngest age groups, we notice a considerable growth also among old adults and the elderly, in the last years [4].

Mobile technologies contribute to the 'datafication' of the (urban) space since social actions are transformed in online data that allow for predictive analysis of people's behavior [5, 6]. The (big) data produced trigger new forms of entrepreneurship that are at the basis of the knowledge economy that is driven by innovation and creativity, giving rise to smart cities [7, 8]. In the Netherlands, one out of five companies carries out analysis in this area, creating new jobs and business opportunities, positioning thus the Netherlands at the forefront in Europe, in this sector [4].

If we look more specifically at ICT use in the Netherlands and we focus on the elderly, statistics [4] reveal that in the age group between 65 and 75 years old, $80 \%$ of the Dutch population made use of Internet in 2016, while the seniors above 75 years old were $50 \%$, as can be seen in Fig. 1. Furthermore, an investigation of the percentage of households with internet access in Fig. 2, shows that The Netherlands, in 2016, were at the forefront within Europe, with $97 \%$ of households being online. Similarly, for the Scandinavian countries, Luxembourg, Great Britain and Germany where 9 of the 10 households have an internet account. The percentage is lower in Southern Europe that is lagging behind, in particular, Italy is quite below the EU average with less than $80 \%$ of the households with Internet. 


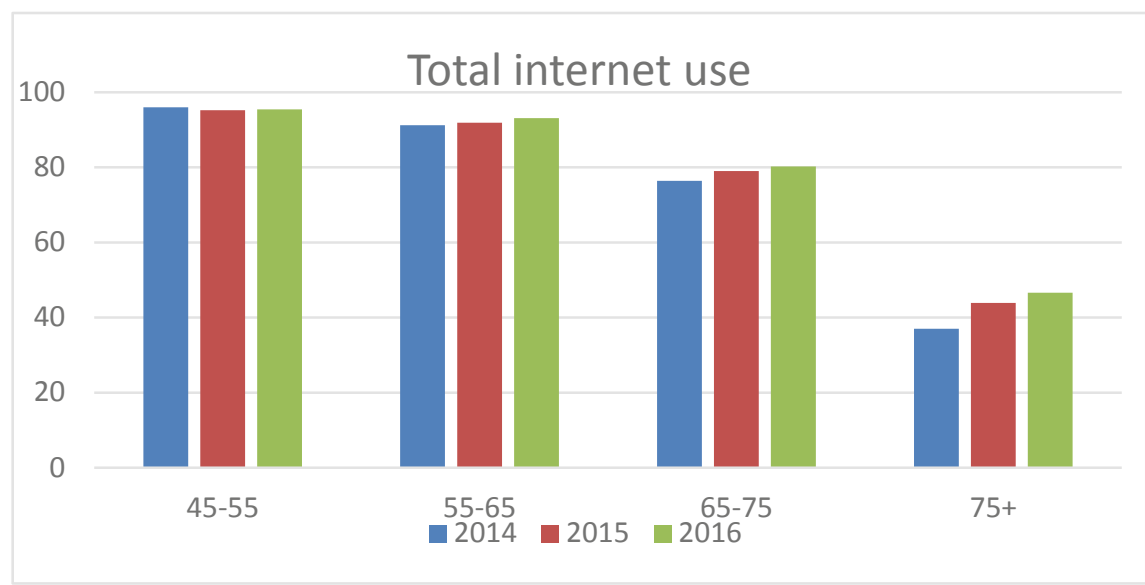

Fig. 1. Internet use in the Netherlands per age group (Source: CBS)

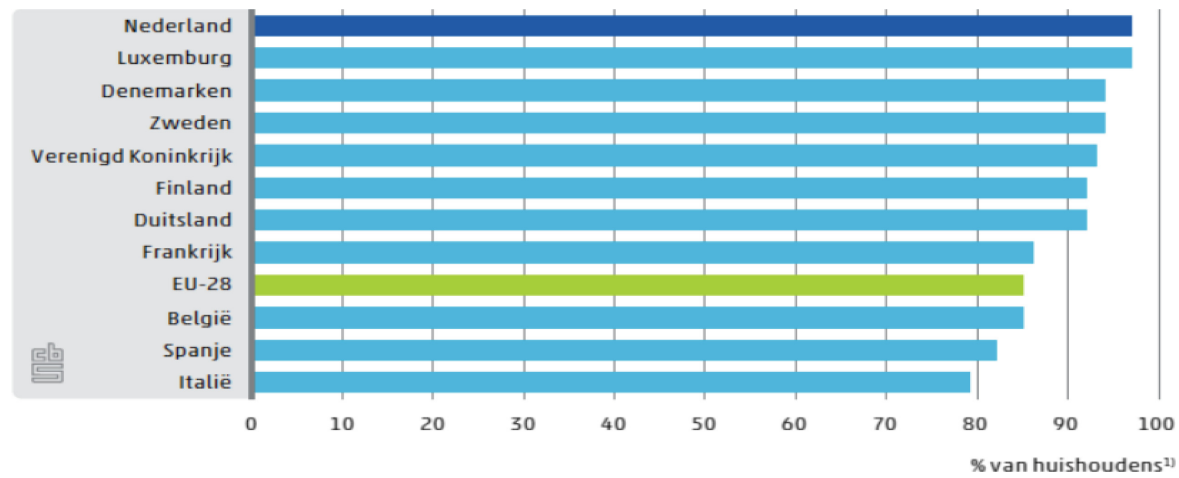

Fig. 2. Households with internet in EU countries 2016 (Source: Eurostat)

It is interesting to analyze, per age group, the type of technology that is being used in order to be online. As can be seen in Fig. 3, the smartphone is the device most used by the youngest age group; in the age group 65 until 75 years old, it is the laptop that is the most used while in the age group of $75+$, the use of the various devices is rather equivalent except for the smartphone that is used less than the others. 


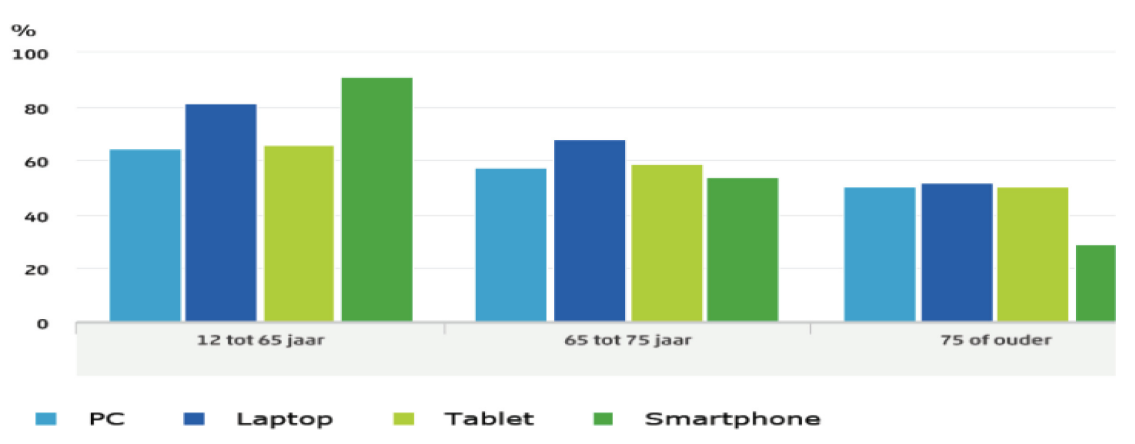

Fig. 3. Devices used to access internet in the Netherlands in 2016 (Source: CBS)

As for the types of activities carried out online among the elderly, Fig. 4 shows that in 2016, the 75+ group uses internet mainly for email (light blue), while almost $70 \%$ of the respondents use it for finding information about goods and services (dark blue) and for banking (light green), around $60 \%$ use it for buying online (dark green) and for finding information about health (orange), more than $50 \%$ use it to read the newspaper (purple). Percentages are higher in the group of 65-75 years old.

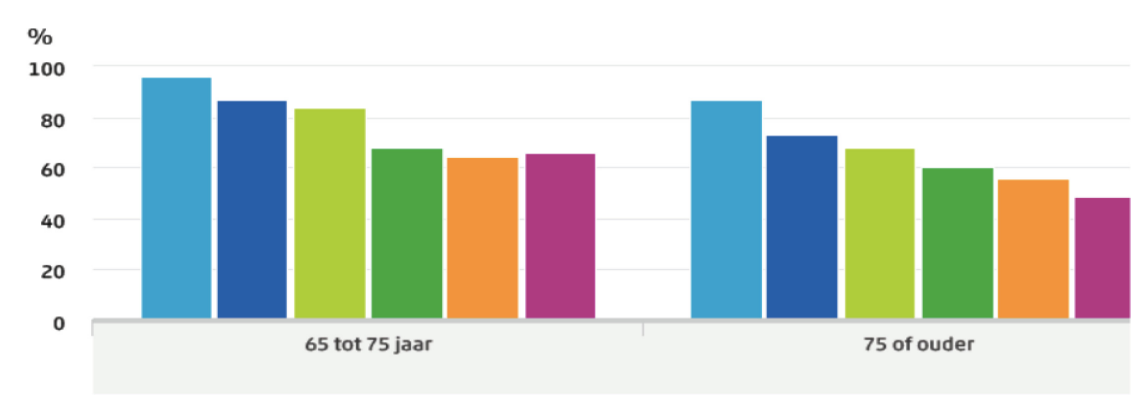

Fig. 4. Internet activities in the Netherlands in 2016 (Source: CBS) (Color figure online)

We can thus conclude that Internet is pervasive in the Netherlands with a high percentage of old adults and the elderly gaining access to it.

If we consider the social media use of the Dutch population, which includes online chatting, writing or reading weblogs, e-mailing and use of social and professional platforms, in 2016, we notice an extended use in all age groups (cf. Fig. 5). Almost $60 \%$ of adults between 65 and 75 years old are active on social media while those above 75 years old are 20\%. If we focus on social networks, in Fig. 6 it is possible to visualize the development in use, in the last years, per age group. Even though young people made more use of social networks than the elderly, the difference has become smaller since 2014. The use in the age group 45-65 years old has registered an increase from $70 \%$ to $83 \%$. In the age group above 65 years old, the increase has been from $26 \%$ to $39 \%$. 


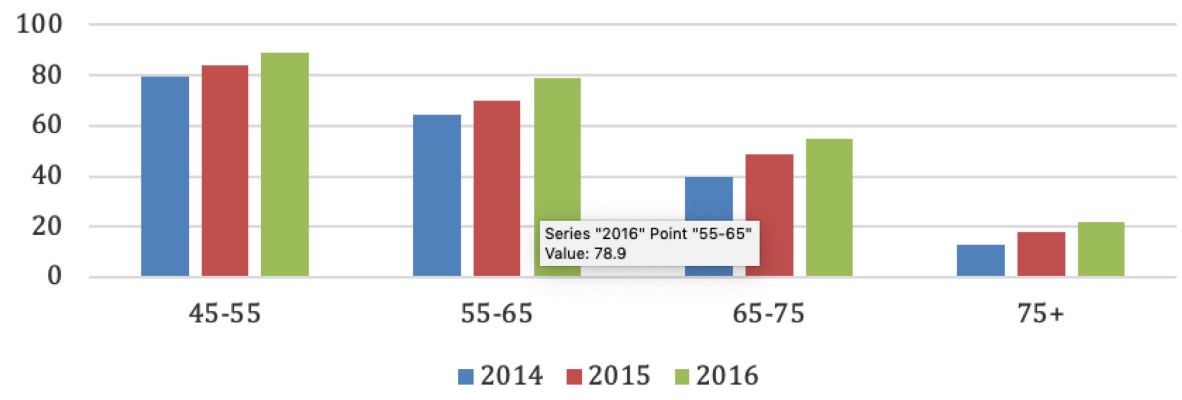

Fig. 5. Social media use in the Netherlands (Source: CBS)

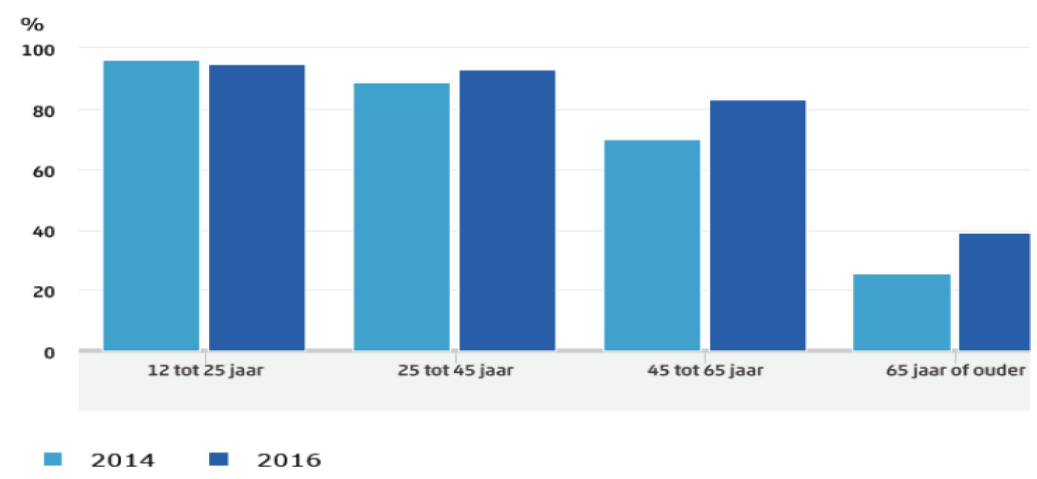

Fig. 6. Social networks use in the Netherlands (Source: CBS)

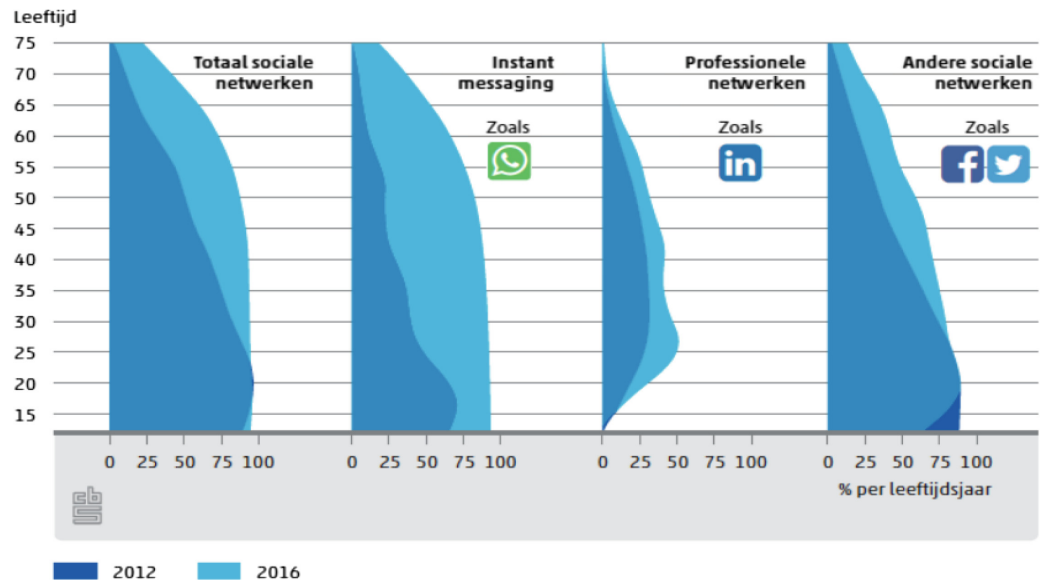

Fig. 7. Use of various social networks in The Netherlands (Source: CBS) (Color figure online) 
Figure 7 shows the development in the use of the various social networks in the years 2012 and 2016. These two years are represented over each other and they partially overlap, in this case the color is grey-blue. It is possible to see that young people use platforms such as Facebook and Twitter less while the elderly are using social networks more, this is especially the case for instant messaging. Furthermore, the use of professional social networks has increased in the age group 22-35 years old.

\section{ICT Use Among Elderly in Italy}

In the previous section, we have shown that the elderly are at the forefront in ICT use in the Netherlands while in this section we analyze the situation in Italy, where we notice striking differences with respect to the analysis previously presented.

The Digital Economy and Society Index tracks the evolution of the European member states in digital competitiveness and it shows the differences attested among its member states. The analysis in [9] shows that the Nordic European countries, among which The Netherlands, are in the first positions while Italy has one of the lowest scores. It occupies the 25 th position among the 28 members states with a digitalization index of 44,3 that is calculated on the basis of connectivity, basic digital competencies, internet use and digitalization of private and public companies. It is almost 30 points behind The Netherlands which is in the fourth position (cf. Fig. 8).

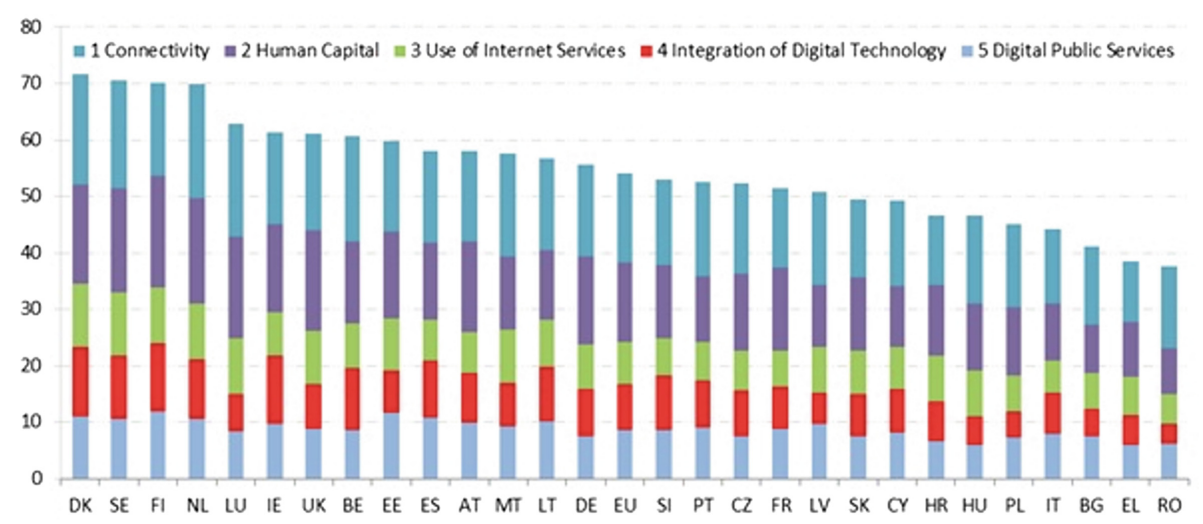

Fig. 8. Digital Economy and Society Index (DESI) 2018 ranking

More specifically, if we consider statistics in internet use [10], there has been a constant growth in Italy, as can be seen in Fig. 9 and a considerable increase in the age group 15-24 years, whose use is above 90\%, furthermore, the users between 55-59 years old have also notably increased. We notice a similar tendency also among the 
elderly even though the percentages in usage are still rather low with only $28.8 \%$ of the population between 65 and 74 years old using internet in 2016 and only $7.7 \%$ of those aged $75+$. This is quite a big difference if compared to The Netherlands. A gender gap in internet use is also attested in Italy: in 2016, 67,6\% of the males were online, against $59 \%$ of the females. Regional differences still play a role and this is the case especially between those regions in Northern Italy $(67,6 \%)$ compared to Southern Italy $(55,9 \%)$ and the islands $(55,7 \%)$, while the Central regions score similarly to the North. Social differences are also attested: while $91,6 \%$ of people with a university degree are online and 93,8 of managers and professionals, the percentage goes down to 63,9\% among those with a middle school diploma and to $77,6 \%$ among factory workers.

\begin{tabular}{|c|c|c|c|c|c|c|c|}
\hline $\begin{array}{l}\text { SESSO, CLASSI DI ETȦ, } \\
\text { RIPARTIZIONI GEOGRAFICHE } \\
\text { E CONDIZIONE OCCUPAZIONALE }\end{array}$ & 2011 & 2012 & 2013 & 2014 & 2015 & 2016 & 2017 \\
\hline Maschi & 56,7 & 58,3 & 60,3 & 62,4 & 65,0 & 67,6 & 69,5 \\
\hline Femmine & 46,7 & 47,1 & 49,8 & 52,8 & 55,8 & 59,0 & 61,3 \\
\hline Totale & 51,5 & 52,5 & 54,9 & 57,5 & 60,2 & 63,2 & 65,3 \\
\hline $6-10$ & 38,3 & 40,8 & 45,1 & 44,6 & 43,8 & 48,2 & 53,7 \\
\hline 11-14 & 78,1 & 76,5 & 80,8 & 80,9 & 80,4 & 82,9 & 86,1 \\
\hline $15-17$ & 89,1 & 88,5 & 89,7 & 91,2 & 92,0 & 91,6 & 93,9 \\
\hline 18-19 & 88,8 & 88,8 & 90,0 & 93,9 & 92,0 & 93,0 & 92,7 \\
\hline $20-24$ & 85,8 & 86,0 & 85,7 & 89,3 & 90,7 & 91,3 & 92,4 \\
\hline $25-34$ & 77,5 & 79,2 & 80,3 & 83,9 & 85,1 & 87,1 & 89,8 \\
\hline $35-44$ & 69,7 & 69,1 & 73,5 & 76,1 & 80,1 & 84,3 & 85,7 \\
\hline $45-54$ & 56,2 & 58,7 & 61,7 & 66,1 & 70,0 & 75,1 & 77,6 \\
\hline $55-59$ & 42,2 & 45,3 & 48,5 & 52,0 & 60,4 & 62,7 & 68,2 \\
\hline $60-64$ & 28,6 & 31,0 & 36,0 & 41,1 & 45,9 & 52,2 & 56,0 \\
\hline $65-74$ & 13,8 & 16,4 & 19,0 & 21,2 & 25,6 & 28,8 & 30,8 \\
\hline 75 e più & 2,7 & 3,3 & 3,5 & 4,4 & 6,7 & 7,7 & 8,8 \\
\hline Totale & 51,5 & 52,5 & 54,9 & 57,5 & 60,2 & 63,2 & 65,3 \\
\hline Nord-ovest & 56,4 & 57,3 & 58,3 & 61,5 & 64,6 & 67,6 & 69,1 \\
\hline Nord-est & 55,9 & 57,7 & 60,1 & 61,5 & 65,2 & 66,9 & 68,0 \\
\hline Centro & 54,5 & 55,1 & 57,8 & 60,4 & 61,6 & 66,4 & 67,8 \\
\hline Sud & 43,6 & 43,3 & 46,6 & 49,2 & 53,1 & 55,9 & 59,1 \\
\hline Isole & 43,9 & 47,3 & 49,8 & 53,0 & 53,8 & 55,7 & 59,6 \\
\hline Italia & 51,5 & 52,5 & 54,9 & 57,5 & 60,2 & 63,2 & 65,3 \\
\hline
\end{tabular}

Fig. 9. Internet use in Italy (Source: Istat)

As for social networks, in 2015, in the age group 65-80 years old, only $14.3 \%$ of the users were on Facebook while only $6.6 \%$ used YouTube [11], as can be seen in Fig. 10 . 


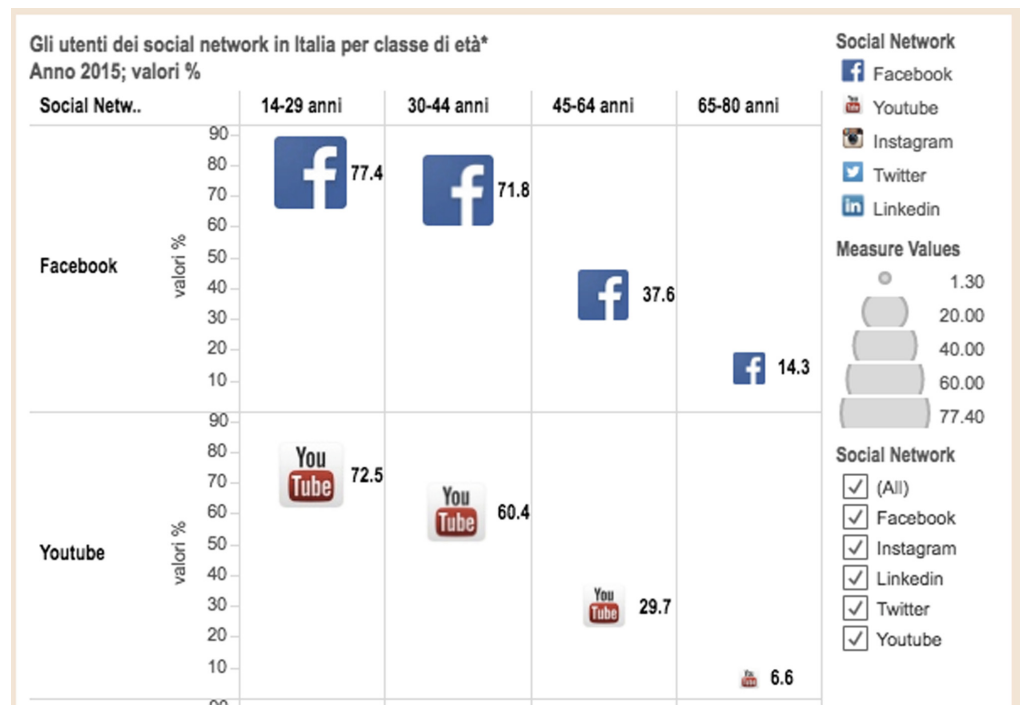

Fig. 10. Social media use in Italy (Source: Censis)

To conclude, while we have seen that in the Netherlands the extended use of Internet and social media triggers the production of big data and a flourishing knowledge economy, the situation is different in Italy where even the digital competence within companies is limited. Only $16,2 \%$ of those companies with 10 people has personnel specialized in ICT and only $12,9 \%$ of them organizes informative sessions on digitalization [10].

\section{ICT Analysis of Italian Elderly in the Grage Project}

The differences with respect to ICT use in The Netherlands and in Italy are quite striking and in the context of the Grage project, we have carried out an exploratory cross-sectional survey in the city of Macerata to gain insights into the reasons for this different behavior and the low penetration of ICT in Italy among the elderly. Macerata is located in the Marche region, which is in central Italy.

We created a tailor-made questionnaire on the basis of a checklist of the essential features of age-friendly cities developed by the WHO [12] to measure the perception of age-friendliness of the urban context the elderly live in. The original WHO checklist, which includes several domains covering physical, social and service environments, has been adapted to the Italian context and we have added additional questions related to ICT and technology, which are of relevance in this paper. The survey comprises 58 items, in addition to 16 demographic questions aiming at assessing the status of the respondents with respect to their personal situation.

The respondents are individuals belonging to two age groups, that is between 55 and 64 (pre-retirement) and older than 64 (retired). We have asked 166 residents, aged on average 64.57, that have provided an answer based on their personal experience and 
their subjective perception. Responses are based on a 6-point Likert scale, ranging from 1 ('strongly disagree') to 6 ('strongly agree'). The questionnaire has been carried out in elderly centers, community halls, summer vacation camps for the elderly, churches, university offices and public offices. Data were collected by means of face-to-face interviews while younger (i.e. between 55 and 67) and literate respondents administered their own questionnaire.

One of the items in the survey asks whether computers and internet are available for free (or for a reasonable price) in public places such as libraries, municipality offices and elderly centers. The majority of the respondents disagree with this statement (i.e. $48 \%$ ), while $20 \%$ didn't answer, responses are visualized in Fig. 11. In Fig. 12, we can see the results of the item that assesses whether there are courses being offered to learn how to use Internet and the various digital services based on it, such as internetbanking, reading news, buying products online or sending emails. In this case, the disagreement is even higher with the statement $(65 \%)$ while $21 \%$ of the respondents didn't answer.

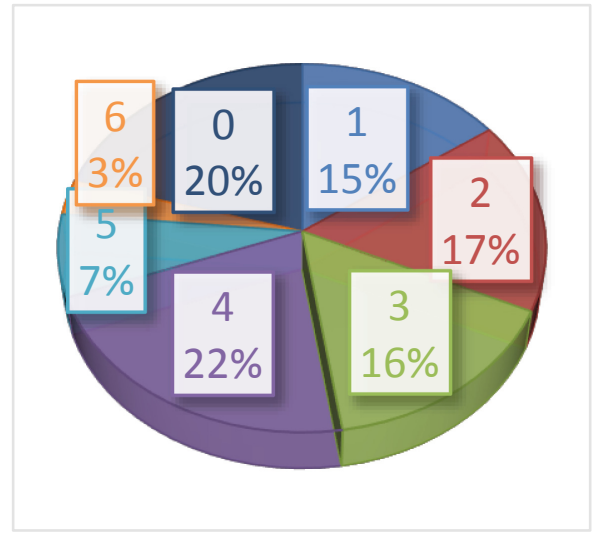

Fig. 11. Availability of computers in public places

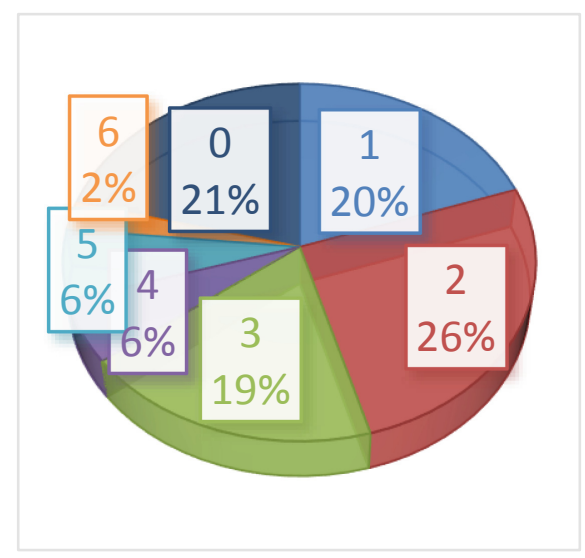

Fig. 12. Internet support

Similar disagreement is attested with respect to the item whether the elderly are aware of social media platforms, such as Facebook and whether they use them to be in touch with family and friends and to receive information. In this case, $67 \%$ disagree while $14 \%$ didn't answer, as can be seen in Fig. 13. However, the majority of the respondents agree that Internet and social media would be very useful for the elderly because they support social inclusion and allow for information to be gained as well as for relations to be maintained with family and friends. As can be seen in Fig. 14, the majority agrees with this statement (59\%) while $10 \%$ didn't answer. 


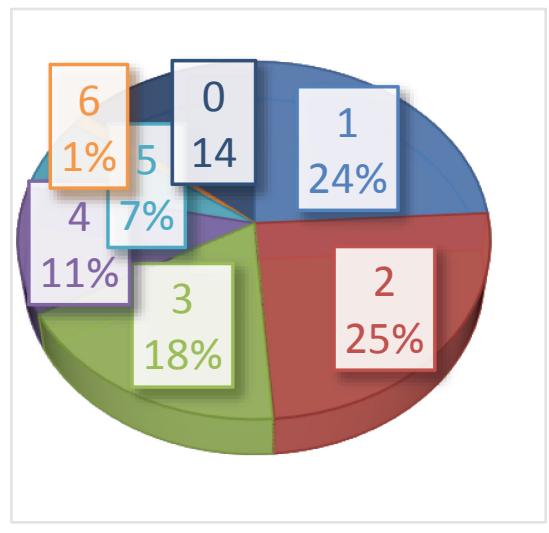

Fig. 13. Elderly and social media use

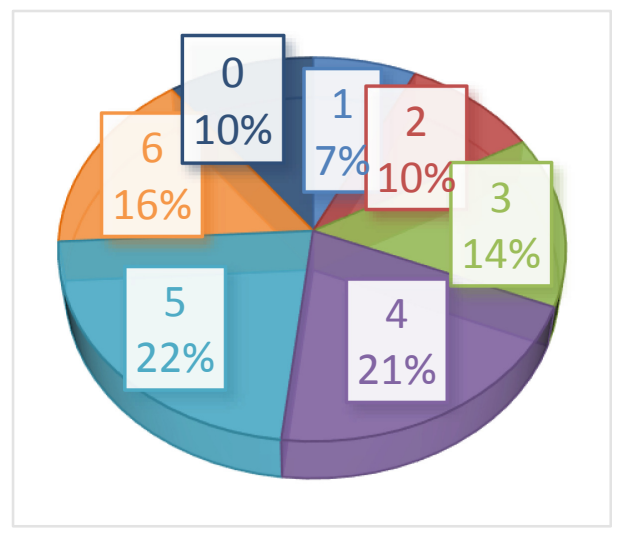

Fig. 14. Usefulness of social media for the elderly

From these responses, we can conclude that the elderly are interested in Internet and social media and they are aware of their potential, but they are limited in their use due to lack of digital competences and limited support through courses to become more acquainted with them.

This conclusion seems to be also supported by an additional survey that we have carried out at regional level to assess the attitude of elderly with respect to ICT, that is whether elderly own devices and whether they are familiar with them. The survey has been filled by 203 respondents from the Marche region, including not only inhabitants of Macerata and its province but also seniors from the other 4 provinces living in small (i.e. less than 30.000 inhabitants) and medium size municipalities (more than 30.000 inhabitants). The average age of the respondents is 73 years old, including both men $(52 \%)$ and women (48\%), with medium-low level of education, of which $76 \%$ were retired.

In the context of this study, four questions are relevant, that is whether the respondents own a computer, an internet connection, a smartphone or a tablet and what is their level of familiarity with them. With respect to the possession of computers, $63 \%$ of the respondents answer that they have one at home, while 32\% don't and 5\% haven't answered. Results are similar with respect to internet connection indicating that people that buy a computer do so to be online. The responses are the same also with respect to familiarity with these devices, that is $11 \%$ of users declare that they don't use them and are not interested in using them, $8 \%$ don't use them but would like to use them, $7 \%$ use them only if somebody helps them, $9 \%$ knows how to use them, but don't use them regularly, only $21 \%$ use them often while $43 \%$ didn't answer.

As for smartphones, the results are the same as for the other two devices with respect to possession, however, regarding familiarity, there are some differences indicating that the elderly are more acquainted with this device. Results indicate that $4 \%$ of users don't use them and are not interested in using them, $4 \%$ don't use them but 
would like to use them, $5 \%$ use them only if somebody helps them, $14 \%$ knows how to use them, but don't use them regularly, only $30 \%$ use them often while $42 \%$ didn't answer.

Differences are attested in ownership of tablets, since $39 \%$ of the respondents have one at home while 54\% don't have one while $6 \%$ didn't answer. As for familiarity with this device, $5 \%$ of users declare that they don't use them and are not interested in using them, $4 \%$ don't use them but would like to use them, $4 \%$ use them only if somebody helps them, $10 \%$ knows how to use them, but don't use them regularly, only $12 \%$ use them often while $64 \%$ didn't answer.

These results indicate that ICT devices are present at home but people tend not to use them often: the percentages of internet and computer use are in line with the national statistics for this age group, discussed in the previous section. Tablets are used less than computers, while smartphones are used the most, but in this case one wonders whether they are used as simple phone or whether all their functionalities are known, including internet use. Interviews with some of the elderly have revealed that the use of apps makes access to services through the smartphone easier for them, especially the use of instant messaging apps such as WhatsApp, that is becoming popular among this population also in Italy. However, the fact that a high percentage of seniors didn't respond might indicate that even though these devices are at home, possibly because they are owned by a younger member of the family, seniors are not much concerned about their use or the possibility to use them or to learn how to use them (cf. low percentages for this option in the survey).

To conclude, it seems that the Italian respondents being asked are aware of the advantages of ICT devices, they have one at home, but they lack information and knowledge on how to use them. The survey has indicated that the reason might be that not enough courses and education tailored for the elderly are available to support them in acquiring ICT skills. This conclusion is in line with a recent report from ISTAT that concludes that while two thirds of Italian family have access to broad band at home, the majority of families without access indicate lack of digital competences as main reason for not being online $(55,5 \%)$ while $25,3 \%$ of the respondents doesn't consider Internet an interesting and useful tool. Economic reasons seem to play a more marginal role and are mentioned only by $16,2 \%$ of the respondents while privacy concerns are mentioned only by $2,4 \%$ of the people being asked [10].

\section{Conclusions}

We have shown, on the basis of detailed statistics [4], that the Netherlands are at the forefront in Internet and Social media use, their adoption includes not only the young generation but also a growing number of old adults as well as the elderly population. The situation is different in Italy that still lags behind in ICT use, which is the case not only for the elderly but also for small enterprises that score low in digital competitiveness $[10,11]$. The reasons, that emerged from the two surveys we have carried out, seem related to lack of digital competences as well as shortage of education opportunities being offered to the elderly to contrast the digital divide. 
In the Netherlands, where the ICT use is widespread, the online activities support the production of data that are at the basis of a flourishing knowledge economy, which relies on big data and behavioral analyses. A problematic side effect of this development is that citizens and social media users, including the elderly, are considered merely as data providers [13]. It is only recently that a debate has emerged in which questions of data ownership are being raised and whether these data benefit the needs of the citizens or instead the interests of the big tech companies [14].

In [15], we have shown that a behavioral analysis of the Dutch elderly based on Twitter data, can be useful to assess their attitude and interests and can have a potential positive impact on urban sustainability and healthy ageing. The analysis of hashtag use reveals that while the younger age groups have an interest in nature and sustainability, this doesn't seem to be the case for the seniors that exhibit, however an interest in locations. We hypothesize that this apparently negative result might reveal that the debate on sustainable development in Twitter revolves around economic and workrelated aspects and it is thus less relevant for the elderly that are not part of the work force since they are usually retired. It is, however, interesting for the younger age groups that use Twitter for work related activities. While initial insights seem to confirm this hypothesis, further research is necessary to validate it and to investigate, on the basis of geo-location information, whether the location hashtags used by the elderly are employed to promote the city they live in. If this is the case, we could conclude that they are more apt to relate to the environment they live in, rather than to abstract concepts such as sustainable development. This interest could be exploited to promote an alternative discourse on sustainable development with social media being employed by the elderly to develop actions in support of the local environment, including environmental policies and volunteering. Activities in the natural environment are restorative experiences and can benefit human beings [16, 17] they tend to involve physical movement and thus promote health, consequently reducing expenditure for health care systems and the connected risks of social marginalization. The Dutch are quite active in this respect given that $49 \%$ of the population, in the period 2012-2016, was involved in volunteering activities and this percentage is even higher among older adults aged $65-75$, raising to $52 \%$ and then decreasing to $34 \%$ for those aged 75 and above [18].

In this view, the elderly would act as innovators and could play an important role in restoring the bond between individuals and the environment which constitutes an essential component of sustainable development [3].

Acknowledgements. This paper is based on results of a project that has received funding from the European Union's Horizon 2020 research and innovation program under the Marie Skłodowska-Curie grant agreement No 645706. This article reflects only the author's view and the REA is not responsible for any use that may be made of the information it contains. I would like to thank Ninfa Contigiani and Giovanna Fanci from the University of Macerata for their support in carrying out the WHO survey. I am also grateful to Daryna Petlina and Olena Motuzenko from Taras Shevchenko National University of Kiev for sharing the results of the regional survey on technology with me. 


\section{References}

1. Wright, S.D., Lund, D.A.: Gray and green? Stewardship and sustainability in an aging society. J. Aging Stud. 14, 229-249 (2000)

2. Grage. https://www.grageproject.eu/

3. Carella, V., Monachesi, P.: Greener through grey? Boosting sustainable development through a philosophical and social media analysis of ageing. Sustainability 10(2), 499 (2018)

4. CBS2017: ICT, kennis en economie 2017. Centraal Bureau voor de Statistiek, Den Haag (2017)

5. Cukier, K., Mayer-Schoenberger, V.: The rise of big data: how it's changing the way we think about the world. Foreign Aff. 92, 28-40 (2013)

6. van Dijk, J.: Datafication, dataism and dataveillance: big data between scientific paradigm and ideology. Surveill. Soc. 12, 197-208 (2014)

7. Kitchin, R.: The real-time city? Big data and smart urbanism. GeoJournal 79(1), 1-14 (2014)

8. Allen, A., Lampis, A., Swilling, M.: Untamed Urbanism. Routledge Advances in Regional Economics, Science and Policy. Routledge, New York (2016)

9. DESI 2018: Digital Economy and Society Index 2018 Report. Digital Single Market, DG Connect (2018)

10. ISTAT2017: Cittadini, Imprese e ICT. ISTAT (2017)

11. Prato, M.: Social network: gli anziani sempre più 'social'. Facebook il piu' popolare tra giovani e anziani. Il sole 24 ore (2016)

12. WHO: Checklist of Essential Features of Age-Friendly Cities. World Health Organization, Geneva, Switzerland (2007)

13. Calzada, I.: (Smart) citizens from data providers to decision-makers? The case study of Barcelona. Sustainability 10(9), 1-25 (2018)

14. Morozov, E.: There is a leftwing way to challenge big tech for our data. Here it is. The Guardian (2018)

15. Monachesi, P., de Leeuw, T.: Analyzing elderly behavior in social media through language use. In: Stephanidis, C. (ed.) HCI 2018. CCIS, vol. 851, pp. 188-195. Springer, Cham (2018). https://doi.org/10.1007/978-3-319-92279-9_26

16. Kaplan, S.: The restorative benefits of nature. Toward an integrative framework. J. Environ. Psychol. 15, 169-182 (1995)

17. Ulrich, R., Simons, R., Losito, B., Fiorito, B., Miles, M., Zelson, M.: Stress recovery during exposure to natural and urban environments. J. Environ. Psychol. 11, 201-230 (1991)

18. CBS Statline. https://statline.cbs.nl/Statweb/ 